\title{
Daya Hambat Krim Minyak Atsiri Herba Boborangan (Hyptis brevipes) sebagai antibakteri terhadap Staphylococcus aureus
}

\section{Inhibition of Cream Containing Essential Oil of Boborongan (Hyptis brevipes) Herbs As An Antibacterial on Staphylococcus aureus}

\author{
Arviani* \& Dwi Larasati \\ Prodi D-III Farmasi, STIKes Madani Yogyakarta \\ Jl. Wonosari Km.10 Karanggayam, Sitimulyo, Piyungan, Bantul, Yogyakarta \\ *corresponding author, email: arviani.ardillah@gmail.com / arviani@stikesmadani.ac.id
}

Manuscript received: 09-12-2020. Accepted: 07-04-2021

\begin{abstract}
ABSTRAK
Boborongan (Hyptis brevipes) secara empiris digunakan dalam etnomedisin mengandung minyak atsiri yang diaplikasikan untuk menghambat pertumbuhan Staphyllococcus aureus. Sediaan krim bersama dengan minyak dalam emulsi air sering digunakan karena kemudahan dan kepatuhan, terutama untuk penggunaan kosmetik dan estetika. Penelitian ini bertujuan mengetahui konsentrasi minimum daya hambat krim minyak atsiri Hyptis brevipes terhadap Staphylococcus aureus. Minyak atsiri Hyptis brevipes diisolasi dengan metode destilasi uap air. Minyak atsiri Hyptis brevipes berbahan dasar krim masing-masing sebesar $0.1 \%$, $0.2 \%$ dan $0.4 \%$. Uji antibakteri menggunakan metode difusi sumuran. Daya hambat antibakteri diperoleh dengan mengamati zona bening pada medium. Hasil pengujian daya hambat antibakteri menunjukan bahwa sediaan krim dengan konsentrasi $0.1 \%, 0.2 \%$ dan $0.4 \%$ menunjukan aktivitas antibakteri dengan diameter hambat masingmasing adalah $5.3 \mathrm{~mm} ; 5.1 \mathrm{~mm}$; dan $6 \mathrm{~mm}$. Oleh karena itu, terbukti bahwa minyak atsiri Hyptis brevipes merupakan kandidat yang menjanjikan untuk bahan antibakteri.
\end{abstract}

Kata kunci: antibakteri; krim; minyak atsiri; Hyptis brevipes; Staphylococcus aureus

\footnotetext{
ABSTRACT

Boborongan (Hyptis brevipes) is empirically used in ethnomedicine containing of essential oil which it is applied to inhibit the growth of the Staphyllococcus aureus. Cream preparation along with oil in water emulsion is often applied due to easiness and compliance particulary for cosmetic and aesthetic use. This study aimed to determine the minimum inhibitory concentration of cream based essential oil of Hyptis brevipes against Staphylococcus aureus. Essential oil from Hyptis brevipes was isolated using the water vapor distillation method. Cream based essential oil of Hyptis brevipes of $0.1 \%, 0.2 \%$, and $0.4 \%$, respectively. Antibacterial activity study was carried out using a well diffusion method. Antibacterial inhibition was obtained by measuring the clear zone on the medium. The results of the antibacterial inhibition test showed that the cream based Hyptis brevipes essential oil along with concentration of $0.1 \%, 0.2 \%$, and $0.4 \%$ showed antibacterial activity with the diameter of inhibition
} 
zone are $5.3 \mathrm{~mm} ; 5.1 \mathrm{~mm}$; and $6 \mathrm{~mm}$, respectively. Therefore, it prooved that the essential oil of Hyptis brevipes was a promising candidate for antibacterial substance.

Keyword: antibacterial; cream; essential oil; Hyptis brevipes; Staphylococcus aureus

\section{PENDAHULUAN}

Genus Hyptis merupakan salah satu jenis tumbuhan yang dimanfaatkan oleh masyarakat sebagai etnomedisin (Wahyono et al. 2012). Hyptis brevipes secara empiris digunakan untuk pengusir nyamuk, sesak nafas, obat batuk, menyembuhkan luka, diare menstruasi tidak teratur; involusi uterus, kekurangan produksi ASI, penanganan paska persalinan dan obat penyakit dalam (Arham et al. 2016; Mahanani, 2018; Roosita et al. 2008; Royyani and Rahayu, 2016; Xu et al. 2013) Minyak atsiri dari herba Hyptis brevipes aktif menginhibisi pertumbuhan bakteri Staphyllococcus aureus dengan nilai MIC 3,125 $\mu \mathrm{g} \mathrm{mL}^{-}$ (Xu et al., 2013).

Staphylococcus aureus adalah patogen manusia utama yang menyebabkan berbagai infeksi klinis. Bakteri ini adalah penyebab utama bakteremia dan endokarditis infektif serta osteoartikular, kulit dan jaringan lunak, pleuropulmonary, dan berbagai infeksi lainnya (Tong et al. 2015). Staphylococcus aureus merupakan salah satu bakteri penyebab jerawat. Beberapa obat jerawat tanpa resep dokter seperti benzoil peroksida, sulfur, dan asam salisilat dapat menimbulkan efek samping berupa iritasi dan tak jarang mengakibatkan parakeratolitik. Penggunaan antibiotik seperti klindamisin, eritromisin, dan tetrasiklin dalam jangka panjang dapat menimbulkan resistensi mikroba serta imunohipersensitivitas (Savitri, 2016)]. Penggunaan sediaan herbal sebagai krim antibakteri merupakan alternatif untuk mengurangi efek samping yang ditimbulkan dan resistensi terhadap antibiotik.

Berdasarkan aktivitas antibakteri minyak atsiri herba boborongan menunjukkan bahwa minyak atsiri herba Hyptis brevipes berpotensi untuk digunakan dalam sediaan kosmetik. Sediaan krim merupakan salah satu bentuk sediaan yang sering digunakan. Tipe krim minyak dalam air (M/A), ditujukan untuk penggunaaan kosmetika dan estetika. Basis krim ini dipilih karena mudah dicuci. Tipe (M/A) mengandung kadar air yang tinggi sehingga memberikan efek hidrasi pada kulit serta meningkatkan penetrasi obat. Kadar air yang tinggi dapat mengurangi resiko peradangan pada penderita jerawat[(Nofriyanti and Wildani, 2019)].

Penelusuran literatur menunjukkan bahwa penelitian mengenai uji aktivitas antibakteri yang diformulasikan ke dalam sediaan krim dari minyak atsiri herba boborongan masih terbatas. Berdasarkan hal tersebut penelitian ini bertujuan mengetahui konsentrasi minimum daya hambat krim minyak atsiri herba boborongan terhadap bakteri Staphylococcus aureus.

\section{BAHAN DAN METODE}

\section{Preparasi Bahan}

Sampel herba boborongan (Hyptis brevipes) dikoleksi dari desa Mayajaya, kecamatan Pamona Selatan, Kabupaten Poso, Sulawesi Tengah. Simplisia tanaman ini telah dilakukan determinasi di Balai Besar Penelitian dan Pengembangan Tanaman Obat dan Obat Tradisional (B2P2TOOT) Tawangmangu. Hal ini dilakukan untuk mencocokkan klasifikasi 
tanaman agar menghindari kesalahan pengumpulan sampel. Sampel herba dikeringkan secara kering angin di ruangan terbuka yang tidak terkena sinar matahari (Xu et al. 2013)

\section{Penyulingan Minyak Atsiri Herba Boborongan}

Penyulingan minyak atsiri dilakukan di laboratorium Center Of Essential Oils Studies (CEOS) Universitas Islam Indonesia (UII). Metode destilasi yang digunakan adalah metode destilasi upa. Sebanyak $1 \mathrm{~kg}$ herba boborongan dimasukkan secara ke dalam dandang kemudian didestilasi selama \pm 6 jam atau dilakukan sampai tidak ada lagi minyak yang menetes. Minyak atsiri hasil destilasi ditambahkan natrium sulfat anhidrat agar didapatkan minyak yang bebas air (Yustica et al. 2019). Total sampel yang dilakukan destilasi $6.65 \mathrm{Kg}$.

Formulasi Krim

Tabel 1. Formulasi Krim Minyak Atsiri

\begin{tabular}{|c|c|c|c|c|c|}
\hline \multirow[b]{2}{*}{ Fase } & \multirow[b]{2}{*}{ Bahan } & \multicolumn{4}{|c|}{ Konsentrasi Bahan } \\
\hline & & $\begin{array}{c}\text { F0 } \\
(0 \%)\end{array}$ & $\begin{array}{c}\text { F1 } \\
(0.1 \%)\end{array}$ & $\begin{array}{c}\text { F2 } \\
(0.2 \%)\end{array}$ & $\begin{array}{c}\text { F3 } \\
(0.4 \%)\end{array}$ \\
\hline \multirow[t]{4}{*}{$\mathrm{A}$} & Minyak atsiri boborongan & 0 & 0,05 & 0,1 & 0,2 \\
\hline & Asam stearat & 7.5 & 7.5 & 7.5 & 7.5 \\
\hline & Cera alba & 12 & 12 & 12 & 12 \\
\hline & Vaselinum album & 8 & 8 & 8 & 8 \\
\hline \multirow[t]{4}{*}{ B } & Trietanolamin & 0.75 & 0.75 & 0.75 & 0.75 \\
\hline & Propilen glikol & 4 & 4 & 4 & 4 \\
\hline & Metil paraben & 0.3 & 0.3 & 0.3 & 0.3 \\
\hline & Akuades (Pelarut ad) & 50 & 50 & 50 & 50 \\
\hline
\end{tabular}

\section{Cara Pembuatan Krim}

Fase A yang merupakan Fase minyak terdiri dari asam stearat, cera alba, vaselinum album dipanaskan sampai melebur sempurna. Fase B yang merupakan fase air (Fase B) yang terdiri dari trietanolamin, propilen glikol, metil paraben, dan akuades dipanaskan diatas kompor sampai larut sempurna. Fase B setelah larut dimasukkan kedalam fase A diaduk kemudian campuran fase A dan fase B dimasukkan kedalam mortir panas diaduk hingga homogen sampai terbentuk masa krim yang baik. Krim yang telah dingin kemudian ditambahkan minyak atsiri kayu manis dan diaduk hingga homogen (Wiguna, 2016) .

\section{Uji Sifat Fisik Krim Minyak Atsiri Herba Boborongan}

Uji sifat fisik yang dilakukan terhadap krim minyak atsiri herba boborongan adalah sebagai berikut :

1) Uji organoleptik

Uji ini menggunakan panca indera atau secara visual. Komponen yang dievaluasi meliputi bau, warna, tekstur sediaan, homogenitas dan konsistensi (Nofriyanti dan Wildani, 2019). 
2) Uji Homogenitas

Sejumlah krim dioleskan pada sekeping kaca transparan secara tipis dan merata. Krim yang homogen jika tidak terdapat gumpalan atau partikel yang tidak tercampur secara merata (Nofriyanti dan Wildani, 2019).

3) $\mathrm{Uji} \mathrm{pH}$

Sejumlah krim dioleskan dioleskan pada kertas indikator universal. Perubahan warna pada kertas indikator kemudian dibandingkan dengan warna dan nilai $\mathrm{pH}$ pada data indikator universal.

4) Uji Daya Sebar

mengetahui kelunakkan sediaan krim ketika dioleskan di kulit. Sejumlah zat tertentu diletakkan di atas kaca yang berskala. Bagian atasnya diberi kaca yang sama, tingkatkan bebannya, dan beri rentang waktu 1-2 menit. Diameter penyebaran diukur pada setiap penambahan beban 50 - 150 gram saat sediaan berhenti menyebar dengan waktu tertentu secara teratur (Kurniawan et al. 2018).

5) Uji Daya Lekat

Sediaan krim harus dapat melekat pada kulit dalam waktu yang cukup lama. Waktu kontak yang cukup memungkinkan krim bekerja dengan efektif terhadap kulit. Syarat waktu daya lekat yang baik untuk sediaan topikal adalah tidak kurang dari empat detik. Sebanyak 0,25 gram krim diletakkan di atas objek gelas. objek gelas dipasang pada alat uji kemudian diberikan objek gelas yang lain di atasnya. Memberikan beban $1 \mathrm{~kg}$ selama 5 menit. Beban $1 \mathrm{~kg}$ dilepas beserta beban penyangga $80 \mathrm{~g}$ dan dicatat waktunya hingga kedua objek gelas tersebut terlepas. [(Kurniawan et al. 2018)]

\section{Uji Antibakteri Minyak Atsiri Herba Boborongan}

Tahapan uji antibakteri boborongan yang dilakukan terhadap krim minyak atsiri herba boborongan adalah sebagai berikut :

1) Persiapan bahan uji antibakteri

Sebanyak 28 gram nutrient agar (NA) dilarutkan dalam $1000 \mathrm{ml}$ akuades, kemudian disterilkan ke dalam autoclave.

2) Pembuatan suspensi bakteri uji

Satu mata ose bakteri diambil dari biakan murni dalam sediaan agar miring kemudian diinokulasi ke dalam media cair steril Nutrient Broth, selanjutnya diinkubasi selama 24 jam pada suhu $37^{\circ} \mathrm{C}$. Kultur bakteri siap digunakan untuk pengujian aktivitas antibakteri.

3) Pengujian aktivitas antibakteri dengan metode difusi sumuran

Media Nutrien Agar (NA) sebanyak $25 \mathrm{ml}$ dicampur dengan $25 \mu \mathrm{L}$ suspensi bakteri uji Staphylococcus aureus, dihomogenkan lalu dituang dalam cawan petri steril dan dibiarkan sampai memadat. Setelah itu dibuat sumur yang berdiameter $\pm 4 \mathrm{~mm}$ dengan menggunakan cork borer. Setiap sumur diisi ekstrak dengan kontrol sebanyak $30 \mu \mathrm{L}$, kemudian diinkubasi selama 24 jam pada suhu $37^{\circ} \mathrm{C}$, selanjutnya diamati dan diukur diameter zona hambat dengan jangka sorong. Kontrol positif menggunakan klindamisin dan kontrol negatif menggunakan formulasi dasar krim. 


\section{HASIL DAN PEMBAHASAN}

Pada penyulingan minyak atsiri dari simplisia herba boborongan (Hyptis brevipes) diperoleh minyak atsiri yang berwarna kekuningan dengan bau khas boborongan. Rendemen yang diperolah sebesar $0,029 \% \mathrm{~b} / \mathrm{v}$. Nilai indeks bias minyak atsiri herba boborongan sebesar 1,5004 .

Hasil pengamatan terhadap uji organoleptis menunjukkan tidak ada perbedaan yang signifikan. Pengamatan terhadap warna masing-masing formula berwarna putih. Formulasi (F4) menunjukan bau yang lebih tajam dibandingkan ketiga formulasi lainnya. Hal ini disebabkan karena konsentrasi minyak atsiri herba boborongan pada formulasi ini lebih tinggi. Data pengamatan $\mathrm{pH}$ krim sebesar 6. Hal ini menunjukkan bahwa krim minyak atsiri herba boborongan tergolong aman digunakan di kulit (Aisyah and Yusuf, 2017).

Tabel 2. Hasil pengujian sifat fisik krim minyak atsiri herba boborongan

\begin{tabular}{|c|c|c|c|c|}
\hline \multirow{2}{*}{ Parameter Uji } & \multicolumn{4}{|c|}{ Formulasi Krim Minyak Atsiri Boborangan } \\
\hline & F0 & F1 & F2 & F3 \\
\hline \multicolumn{5}{|l|}{ Organoleptis } \\
\hline Bentuk & Kental & Kental & Kental & Kental \\
\hline Warna & Putih & Putih & Putih & Putih \\
\hline \multirow[t]{2}{*}{ Bau } & Khas & Khas & Khas & Khas \\
\hline & boborongan & boborongan & boborongan & boborongan \\
\hline Homogenitas & Homogen & Homogeny & homogen & Homogeny \\
\hline Daya lekat $(\mathrm{g} \mathrm{cm} / \mathrm{s})$ & 8.18 & 4.51 & 2.41 & 3.18 \\
\hline Daya Sebar $\left(\mathrm{cm}^{2}\right)$ & 2.70 & 3.77 & 3.97 & 4.28 \\
\hline $\mathrm{pH}$ & 6 & 6 & 6 & 6 \\
\hline Tipe Emulsi & $\mathrm{m} / \mathrm{a}$ & $\mathrm{m} / \mathrm{a}$ & $\mathrm{m} / \mathrm{a}$ & $\mathrm{m} / \mathrm{a}$ \\
\hline \multirow[t]{4}{*}{ Keterangan : } & \multicolumn{4}{|c|}{$\mathrm{F} 0=$ formulasi krim tanpa minyak atsiri herba boborongan } \\
\hline & \multicolumn{4}{|c|}{$\mathrm{F} 1=$ formulasi $0,1 \%$ minyak atsiri herba boborongan } \\
\hline & \multicolumn{4}{|c|}{$\mathrm{F} 2=$ formulasi $0,2 \%$ minyak atsiri herba boborongan } \\
\hline & \multicolumn{4}{|c|}{$\mathrm{F} 3=$ formulasi $0,4 \%$ minyak atsiri herba boborongan } \\
\hline
\end{tabular}

Pengujian daya sebar untuk mengetahui seberapa baik kemampuan sediaan menyebar di permukaan kulit. Daya sebar dapat mempengaruhi kemampuan absorbsi obat dan kecepatan pelepasan zat aktif di tempat pemakaiannya. Sediaan cenderung lebih disukai jika dapat menyebar dengan baik, mudah di kulit serta nyaman digunakan (Aisyah dan Yusuf, 2017). Daya sebar krim minyak atsiri boborongan berkisar antara $2.7-4.28 \mathrm{~cm}^{2}$. Hal ini menunjukkan bahwa krim belum memiliki daya sebar yang baik. Persyaratan daya sebar yang baik untuk sediaan topikal $5-7 \mathrm{~cm}^{2}$ [(Kurniawan et al. 2018)].

Pengujian daya lekat krim bertujuan mengetahui kemampuan sediaan melekat dan melapisi permukaan kulit sewaktu digunakan. Daya lekat pada sediaan topikal dikatakan baik jika tidak kurang dari 4 detik. Data hasil pengamatan krim minyak atsiri herba boborongan pada formulasi F2 telah memenuhi persyaratan daya lekat yang baik sebesar 4.51 detik. Formulasi F3 dan F4 belum memenuhi persyaratan karena hanya berkisar 2 - 3 detik. (Aisyah and Yusuf, 2017).

Antibakteri merupakan suatu zat atau bahan yang dapat menghambat atau membunuh pertumbuhan bakteri. Pengujian terhadap daya hambat antibakteri ditujukan untuk 
mengetahui kemampuan daya hambat zat aktif minyak atsiri boborongan terhadap bakteri Staphylococcus aureus dengan melihat zona bening pada media biakan nutrient agar. Data diameter zona hambat disajikan pada tabel 3.1.

Tabel 3.1. Hasil pengukuran daya hambat formula krim minyak atsiri herba boborongan

\begin{tabular}{clccc}
\hline \multicolumn{1}{c}{ Bakteri Uji } & \multicolumn{2}{c}{ Formulasi } & $\begin{array}{c}\text { Daya Hambat } \\
(\mathbf{m m})\end{array}$ & Keterangan \\
\hline Staphylococcus aureus & $\begin{array}{l}\text { Minyak atsiri } \\
\text { boborongan } 100 \%\end{array}$ & 17 & herba \\
& F1 & 5.3 & Leman \\
& F2 & 5.1 & Lemah \\
& F3 & 6.5 & Lemah \\
& & Kontrol positif & 15.2 & Lemah \\
& Kontrol negatif & 0 & Lemah \\
\hline
\end{tabular}

Keterangan : $\quad$ Daya hambat sudah termasuk diameter lubang sumuran sebesar $\pm 4 \mathrm{~mm}$

$\mathrm{F} 1=$ formulasi $0,1 \%$ minyak atsiri herba boborongan

$\mathrm{F} 2$ = formulasi $0,2 \%$ minyak atsiri herba boborongan

$\mathrm{F} 3$ = formulasi $0,4 \%$ minyak atsiri herba boborongan

Kontrol negatif $=\mathrm{F} 0=$ formulasi tanpa minyak atsiri herba boborongan

Kontrol positif = gel klindamisin $1 \%$

Pengujian terhadap minyak atsiri herba boborongan (Hyptis brevipes) 100\% tanpa pengenceran menunjukkan aktivitas daya hambat yang sedang dengan diameter zona hambat $17 \mathrm{~mm}$. Berdasarkan data tersebut kemudian dilakukan formulasi sediaan krim dengan menggunakan konsentrasi minyak atsiri herba boborongan masing-masing sebesar $0.1 \%$, $0.2 \%$ dan $0.4 \%$. Hasil pengamatan menunjukkan bahwa pada konsentrasi minimum $0.1 \%$ telah menunjukkan aktivitas daya hambat terhadap bakteri Staphylococcus aureus. Terbentuknya zona bening dengan diameter $5 \mathrm{~mm}$. Pada formulasi F3 krim minyak atsiri herba boborongan dengan konsentrasi $0.4 \%$ menunjukkan zona hambat sebesar $6.5 \mathrm{~mm}$. Peningkatan konsentrasi menunjukkan peningkatan zona diameter zona hambat terhadap bakteri tersebut.

Hasil penelusuran literatur menunjukkan bahwa pada minyak atsiri boborongan (Hyptis brevipes) yang berasal dari Sanya provinsi Hainan mengandung senyawa mayor yaitu 3Allylguaiacol (62.67\%) dan metil eugenol (19.46\%). Kandungan 3-Allylguaiacol yang memiliki kemiripan struktur dengan eugenol diduga memiliki aktivitas antibakteri (Xu et al. 2013). Eugenol adalah senyawa yang bersifat lipofilik yang dapat mendisrupsi membran sitoplasma pada bakteri. Hal tersebut dapat meningkatan permeabilitas pada sel sehingga menyebabkan terjadi kebocoran ion dan hilangnya protein intraseluler, sehingga terjadi kematian sel (Panuluh, 2019).

\section{KESIMPULAN}

Sediaan krim minyak atsiri herba boborongan (Hyptis brevipes) pada konsentrasi minimum $0.1 \%$ telah memiliki daya hambat terhadap bakteri Staphylococcus aureus. 
Semakin tinggi konsentrasi minyak atsiri pada krim maka sifat antibakteri semakin meningkat. Oleh karena itu minyak atsiri herba boborongan (Hyptis brevipes) merupakan kandidat yang menjanjikan untuk bahan antibakteri.

\section{Ucapan Terimakasih}

Peneliti mengucapkan terima kasih kepada Kemenristekdikti atas dana penelitian yang telah diberikan melalui skema Penelitian Dosen Pemula (PDP) tahun 2020 dengan nomor kontrak 1625.39/LL5/PG/2020.

\section{DAFTAR PUSTAKA}

Aisyah, A. N., Yusuf, N. A. 2017. Formulasi Emulgel Ekstrak Etanol Daun Murbei ( Morus alba L .) Dengan Variasi Konsentrasi Emulgator Span $80 \AA$ dan Tween 80 ('. Journal of Pharmaceutical and Medicinal Sciences. 2(2): 77-80.

Arham, S., Khumaidi, A., Pitopang, R. 2016. Keanekaragaman jenis tumbuhan obat tradisional dan pemanfaatannya pada suku kulawi di desa mataue kawasan taman nasional lore lindu. Jurnal Biocelebes. 10(2): 01-16.

Kurniawan, M. F., Sugihartini, N., Yuwono, T. 2018. Permeabilitas dan Karakteristik Fisik Emulgel Minyak Atsiri Bunga Cengkeh dengan Penambahan Enhancer. Medical Sains: Junal Ilmiah Kefarmasian. 3(1): 1-10.

Mahanani, A.U. 2018. Studi Potensi Gulma Sebagai Tanaman Obat di Kabupaten Jayawijaya. Agrotek. 4(7): 31-37.

Nofriyanti, Wildani. 2019. Formulasi Krim Dari Ekstrak Air Daun Alpukat ( Persea americana Mill .) Sebagai Sediaan Anti Jerawat. Jurnal Penelitian Farmasi Indonesia. 7(2): 51-56.

Panuluh, P.D. 2019. Potensi Cengkeh (Syzigium aromaticum) sebagai Antibakteri Methicillin Resistant Staphylococcus aureus (MRSA). Jurnal Ilmiah Kesehatan Sandi Husada. 10(2): 270-274.

Roosita, K., Kusharto, C.M., Sekiyama, M., Fachrurozi, Y., Ohtsuka, R. 2008. Medicinal plants used by the villagers of a Sundanese community in West Java, Indonesia. Journal of Ethnopharmacology. 115(1): 72-81.

Royyani, M.F., Rahayu, M. 2016. Pengetahuan Lokal Tumbuhan Obat Masyarakat Desa Dompo-Dompo Jaya, Pulau Wawonii - Sulawesi Tenggara. Jurnal Teknologi Lingkungan, 11(2): 157-166

Savitri, A.A. 2016. Formulasi Sediaan Krim Ekstrak Etanol Buah Mahkota Dewa (Phaleria macrocarpa (Scheff.)Boerl) dengan basis vanishing cream dan uji aktivitas antibakteri terhadap Staphylococcus epidermidis. Naskah publikasi. Universitas Muhammadiyah Surakarta. Surakarta

Tong, S.Y.C., Davis, J.S., Eichenberger, E., Holland, T.L., Fowler, Jr. V.G., 2015. Staphylococcus aureus infections: Epidemiology, pathophysiology, clinical manifestations, and management. Clinical Microbiology Reviews. 28(3): 603-661.

Wahyono, S. Wahyono, S., Widowati, L., Mujahid, R., Subositi, D., Widiyastuti, Y., Haryanti, S., Junediono, Jokopriyambodo, W., Budiarti, M., Maruzy, A., Indrian M, F., 
Sari, A.N. 2012. Eksplorasi Pengetahuan Lokal Etnomedisin. Lembaga Penerbitan Badan Litbangkes, Jakarta.

Wiguna, P.A. 2016. Formulasi Sediaan Krim Minyak Atsiri Kayu Manis (Cinnamomum burmannii) dengan Basis Vanishing Cream dan Uji Aktivitas Antibakterinya Terhadap Staphylococcus Epidermidis. Naskah publikasi. Universitas Muhammadiyah Surakarta. Surakarta

Xu, D.H., Huang, Y.S., Jiang, D.Q., Yuan, K. 2013. The essential oils chemical compositions and antimicrobial, antioxidant activities and toxicity of three Hyptis species. Pharmaceutical Biology. 51(9):1125-1130.

Yustica, F.K., Widiastuti, N.I., Sapitri, N., Fitriastuti, D. 2019. Essential oils from Alpinia purpurata (Zingiberaceae): Chemical composition and Formulation of antiacne cream. Indonesian Journal of Chemical Research. 4(1): 14-21. 